\title{
Biophysical profile of blood pressure in urban school children
}

\author{
Koolla Pavan Kumar ${ }^{1}$, S. Srikrishna ${ }^{2}$, P. S. Murthy ${ }^{3}$, Reddy P. ${ }^{4}$ \\ ${ }^{1}$ Dr. K. Pavan Kumar, Assistant Professor, Department of Pediatrics, MNR Medical College \& Hospital, Sangareddy, \\ Telangana, ${ }^{2}$ Dr. S. Srikrishna, Consultant Pediatrician, NICE Foundation, ${ }^{3}$ Dr. P. S. Murthy, Head of the Department, \\ Pediatrics, NICE Hospital, ${ }^{4}$ Dr. Padmanabha Reddy, CEO, NICE Foundation, Hyderabad.
}

Corresponding Author: Dr. S. Srikrishna, 2/3RT, Near Community Hall, Sanjevreddy Nagar, Hyderabad.

\begin{abstract}
Background: A Systematic review \& meta-analysis revealed that there is 'Strong evidence for tracking of Blood pressure from childhood to adulthood i.e., the Children in the upper percentile of Blood Pressure levels are more likely to become hypertensive in adulthood. Objective: To study the prevalence of Pre-hypertension \& Hypertension and the relationship of Blood Pressure with variables like age, sex, weight, height, body Mass Index (BMI), Socioeconomic status and Family history in Urban school children. Materials \& Methods: The present Cross-sectional study conducted in urban school children, Hyderabad. Total 2500 children of 5-14 years age group were involved in the study group; children were selected in random sampling method. Results: The Prevalence of Hypertension among children between 5 -14 yrs was $7.2 \%$ (6.6\% in Boys \& $7.9 \%$ in girls). Pre-hypertension prevalence was found higher in boys $(6.2 \%)$ compared to girls (3\%). Multiple Regression Analysis showed Positive and significant correlation of age, weight, height with each systemic blood pressure and diastolic blood pressure ( $\mathrm{P}$ value $<0.001$ ). Conclusion: Regular Blood pressure measurement of children is mandatory for early detection of Pre-hypertension \& hypertension.
\end{abstract}

Keywords: Biophysical profile, Blood pressure, BMI, Hypertension, Pre-hypertension, Urban School Children, Systolic blood pressure and diastolic blood pressure

\section{Introduction}

Hypertension, a Modern Epidemic, is one of the major risk factors for coronary heart disease \& stroke, the leading causes of morbidity and mortality across the world [1]. It was documented that almost $75 \%$ of cases of Hypertension and 90\% cases of Pre- hypertension in children and adolescents are undiagnosed - an Iceberg Disease [2,3].

A Systematic review \& meta-analysis revealed that there is 'Strong evidence for tracking of Blood pressure from childhood to adulthood' i.e., the Children in the upper percentile of Blood Pressure levels are more likely to become hypertensives in adulthood [4]. Hence, early recognition of hypertension \& its risk factors in children may help in preventing cardiovascular diseases in later life by altering lifestyle [5,6]. It is essential to have a local reference data, as the reference norms varies with racial, ethnical \& cultural differences across the world [7]. Studies pertaining to blood pressure of Indian school children are very few and there is no published data from Telangana so far.

Manuscript received: $18^{\text {th }}$ January 2018

Reviewed: $28^{\text {th }}$ January 2018

Author Corrected: $4^{\text {th }}$ February 2018

Accepted for Publication: $9^{\text {th }}$ February 2018

\section{Material and Methods}

Type of study: A cross sectional study

Place of study: The study was conducted under NICE Foundation- School child Health care plan and MNR Schools of Excellence.

Sampling method: Random Selection

Inclusion criteria: Apparently healthy children between the age group of 5-14 yrs.

Exclusion Criteria: age below 5 yrs and above 14 yrs and those known to be suffering from severe anaemia, cardiac or renal diseases.

Statistical method: Statistical analyses were performed by using SPSS version 18.0. A stepwise regression analysis was carried out.

This study conducted on 2500 children in the age group of $5-14$ years from 20 randomly selected schools of Hyderabad city and MNR Schools of excellence during August 2015 - June 2016. The study was conducted under NICE Foundation- School Child Health care plan. 
Clinical examination was carried out at their school between 8:00 AM to 12:00 noon after prior information of procedure to the children $\&$ their parents. Each child in the class was given questionnaires in vernacular language, designed to obtain information regarding socio - economic status \& family history of hypertension in the parents.

The child's age was recorded as the completed years as entered in the school register. Volunteers were trained to record Height \& weight using standardized method. Socioeconomic status of the family was assessed by modified B.G Prasad classification (Oct 2000) into grade I-V.

Before recording blood pressure, the procedure was explained to children and sufficient time was given to allay anxiety and fear. Blood pressure was recorded in sitting position in right arm by auscultatory method using standard mercury sphygmomanometer with a set of different sized cuffs. The first and fifth phases of Korotk off sounds were taken as indicative of the systolic and diastolic blood pressures respectively and definitions of hypertension \& pre-hypertension were as per the current Fourth task force report guidelines on the diagnosis, evaluation, and treatment of high blood pressure in children and adolescents. Blood pressure was recorded three times and the lowest reading was taken for analysis. For children who have recorded high blood pressure, the factors like anxiety and fear were removed and re-recorded after one hour of rest.

Statistical analyses were performed by using SPSS version 18.0. A stepwise regression analysis was carried out to find principal determinants of blood pressure with independent variables such as age, sex, height and BMI.

Pearson's correlation coefficient was determined to assess the relationship of blood pressure with these variables. Children with history of or suffering from acute or chronic illness, with signs of anemia, cardiac \& renal disorder on medical examination were excluded from the study.

\section{Results}

Blood Pressure of 2500 students was recorded \& 50 students could not be followed up during second visit. Out of 2450 students, 1330 were Boys and 1120 were Girls.

Our result revealed 7.2\% (177) prevalence of hypertension. Out of 177 children found to be hypertensive, 88 were boys and 89 were girls.

The prevalence of hypertension was $6.6 \%$ in boys and $7.9 \%$ in girls. Blood pressure values equal to \& above $90^{\text {th }}$ percentile but less than $95^{\text {th }}$ percentile were taken as prehypertension. Our result revealed $4.7 \%$ prevalence of Pre hypertension with twice i.e., $6.2 \%$ in Boys than in girls (3\%).

Table-1: Comparison of Mean Systolic \& Diastolic BP in different age groups.

\begin{tabular}{|c|c|c|c|c|}
\hline Age & \multicolumn{2}{|c|}{ Boys } & \multicolumn{2}{c|}{ Girls } \\
\hline Yr $)$ & SBP & DBP & MBP & DBP \\
\hline & Mean +/- sd & Mean $+/-$ sd & Mean $+/-$ sd & $57.9+/-4.9$ \\
\hline 5 & $96.1+/-5.9$ & $59.6+/-5.5$ & $95.6+/-8.5$ & $59.2+/-4.9$ \\
\hline 6 & $97.0+/-6.8$ & $59.3+/-5.3$ & $97.1+/-5.4$ & $63.2+/-5.0$ \\
\hline 7 & $101.9+/-7.1$ & $62.7+/-6.3$ & $102.4+/-5.6$ & $64.9+/-4.8$ \\
\hline 8 & $102.4+/-8.3$ & $63.8+/-6.4$ & $104.7+/-6.3$ & $65.5+/-6.2$ \\
\hline 9 & $104.2+/-8.0$ & $65.4+/-6.4$ & $104.1+/-8.8$ & $62.9+/-6.5$ \\
\hline 10 & $104.5+/-8.4$ & $66.7+/-6.0$ & $98.7+/-7.3$ & $65.7+/-6.2$ \\
\hline 11 & $106.3+/-8.1$ & $67.8+/-6.1$ & $104.6+/-7.7$ & $67.9+/-4.9$ \\
\hline 12 & $107.9+/-7.4$ & $69.6+/-6.5$ & $107.2+/-7.6$ & $71.6+/-4.7$ \\
\hline 13 & $111.1+/-7.0$ & $70.4+/-4.9$ & $109.7+/-7.2$ & $72.8+/-4.4$ \\
\hline 14 & $114.1+/-4.5$ & $73.3+/-3.9$ & $111.9+/-7.2$ & sd \\
\hline
\end{tabular}




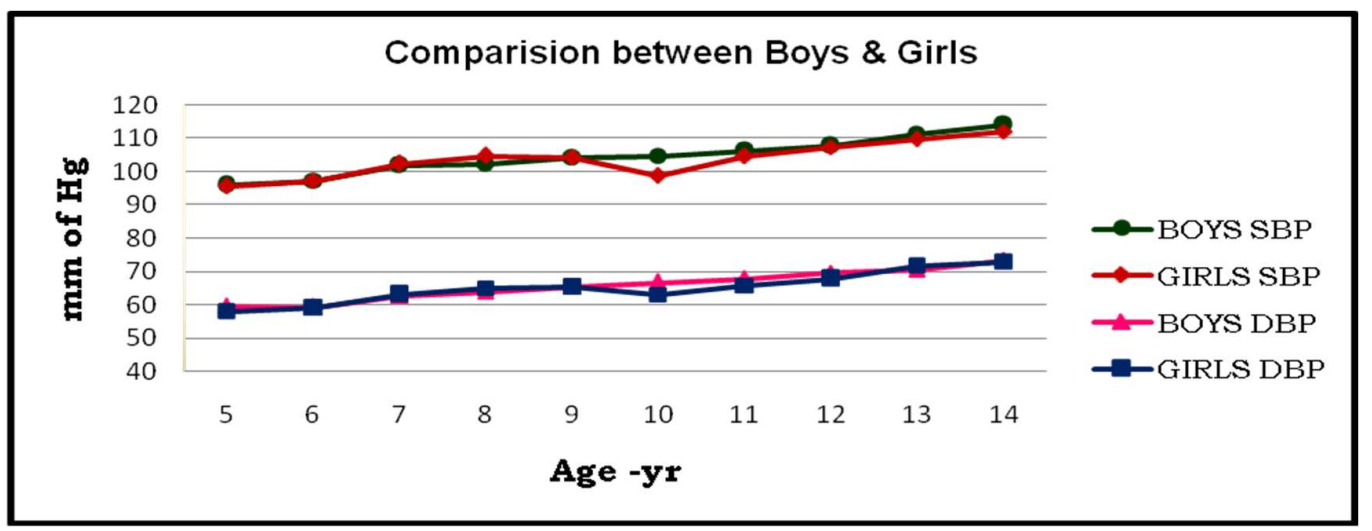

Figure-1: Showing comparison of SBP \& DBP in between boys and girls

There is gradual increase in mean systolic \& diastolic blood pressure with increase in Age. There was no significant difference between the SBP as well as DBP of boys \& girls in most age groups except for difference between the SBP at 10 and $14 \mathrm{yr}$ and between DBP at $10 \mathrm{yr}$.

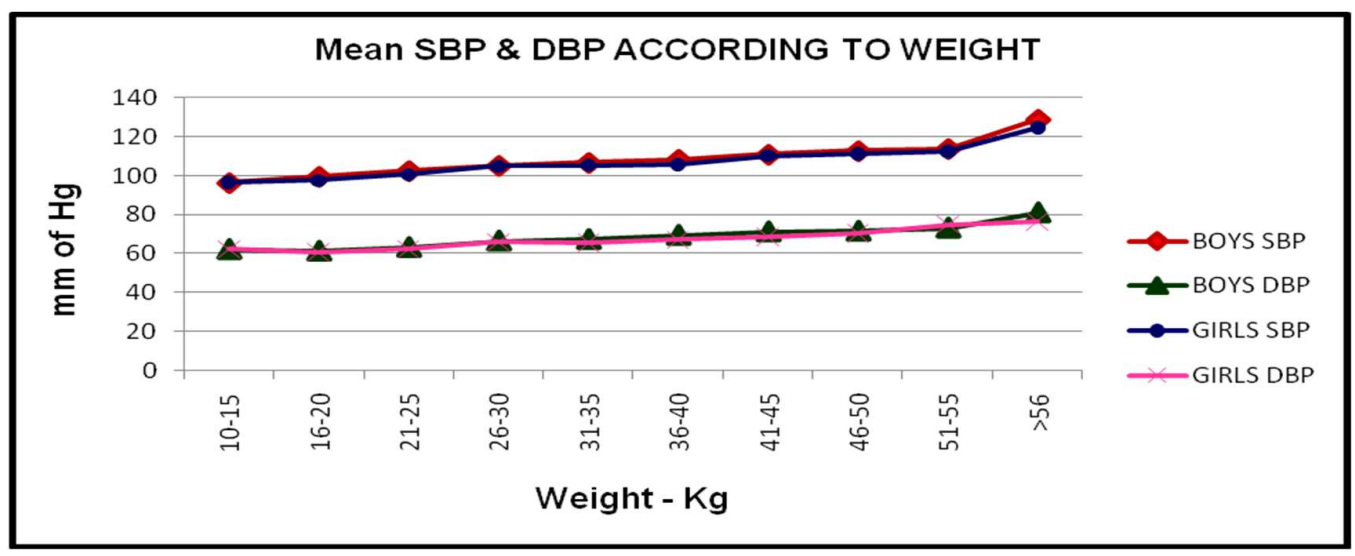

Figure-2: Showing Mean SBP \& DBP depends on weight.

We have observed that as the weight increases there is gradual increase in both mean systolic and diastolic blood pressure in both boys and girls and sharp increase in both mean systolic and diastolic blood pressure in $>56 \mathrm{~kg}$ age group

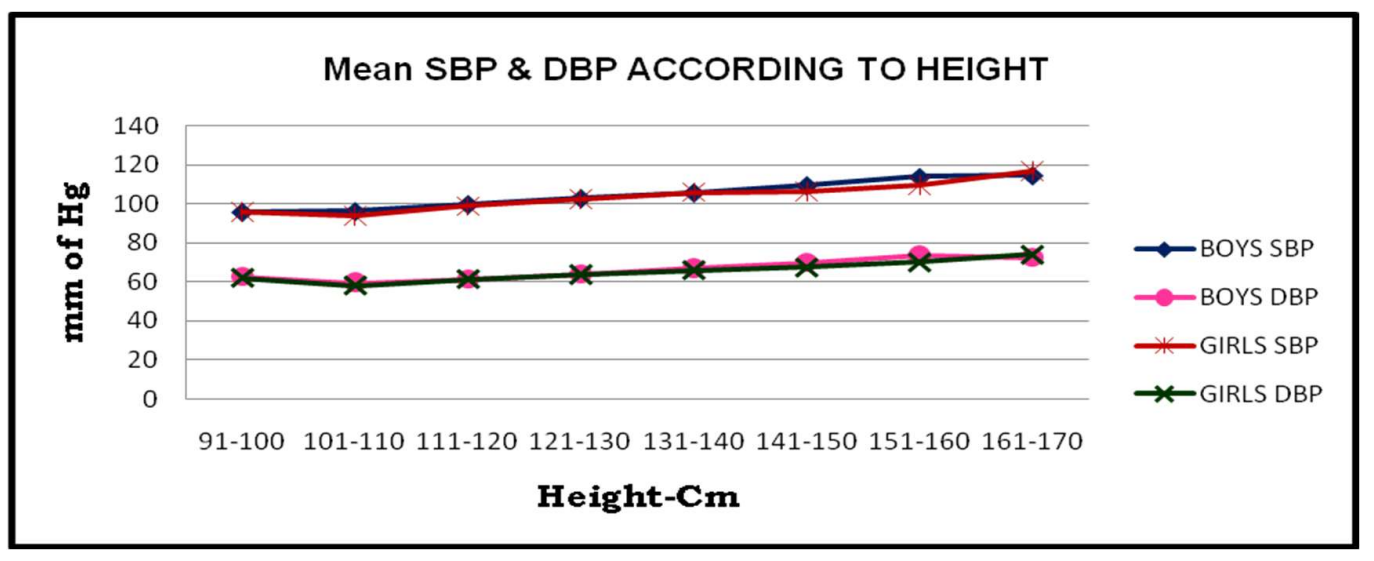

Figure-3: Showing Mean SBP \& DBP depends on height.

It is observed that as the height increases, Systolic Blood Pressure increased gradually in both sexes. There is rapid increase in Diastolic Blood Pressure after $110 \mathrm{~cm}$ of height in Boys \& Girls. 
Editorial

Table-2: Distribution of BP according to Body Mass Index.

\begin{tabular}{|c|c|c|c|c|c|c|}
\hline \multirow{2}{*}{ BMI kg/m2 } & \multicolumn{3}{|c|}{ BOYS } & \multicolumn{3}{c|}{ GIRLS } \\
\cline { 2 - 7 } & \multirow{2}{*}{$\mathbf{n}$} & SBP & DBP & $\mathbf{n}$ & SBP & DBP \\
\cline { 2 - 7 } & & Mean & Mean & & Mean & Mean \\
\hline$<5$ & 509 & 102.4 & 64.6 & 367 & 102.6 & 65.1 \\
\hline $5-85$ & 694 & 103 & 64.3 & 596 & 101 & 62.6 \\
\hline $85-95$ (overweight) & 116 & 109.4 & 69.8 & 141 & 108.4 & 67.7 \\
\hline$>=95$ (obesity) & 8 & 123.3 & 76 & 16 & 113.8 & 71.4 \\
\hline
\end{tabular}

We have observed that the means of Systolic and Diastolic Blood Pressure in obesity group (123.3 $\mathrm{mm}$ of $\mathrm{Hg} \& 76 \mathrm{~mm}$ of $\mathrm{Hg}$ ) were significantly higher than overweight group (109.4 mm of $\mathrm{Hg} \& 69.8 \mathrm{~mm} \mathrm{of} \mathrm{Hg}$ ), while that in overweight group was significantly higher than normal weight group $103 \mathrm{~mm}$ of $\mathrm{Hg} \& 64.3 \mathrm{~mm}$ of $\mathrm{Hg}),(\mathrm{P}<0.0001)$. Similar observations were noted in girls.

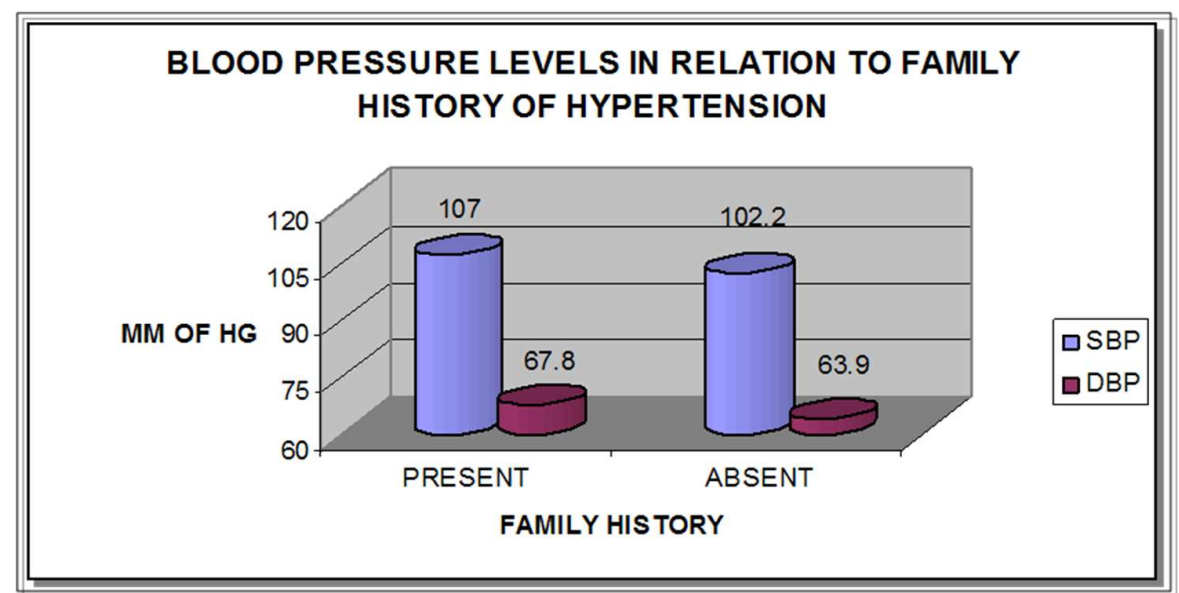

Figure-4: Showing the BP levels in relation to family history of Hypertension.

Children with Family History of Hypertension had higher values of mean SBP (107mm of Hg) and mean DBP (67.8 mm of $\mathrm{Hg}$ ) than the children who do not have the family history of hypertension, whose mean SBP was $102.2 \mathrm{~mm}$ of $\mathrm{Hg}$ and the mean DBP was $63.9 \mathrm{~mm}$ of $\mathrm{Hg}$. This difference is found to be statistically significant $(\mathrm{P}<0.001)$.

Our study shows Family history of hypertension in one or both parents was present in $16.8 \%$ children with high blood pressure compared to $6 \%$ in normotensive parents.

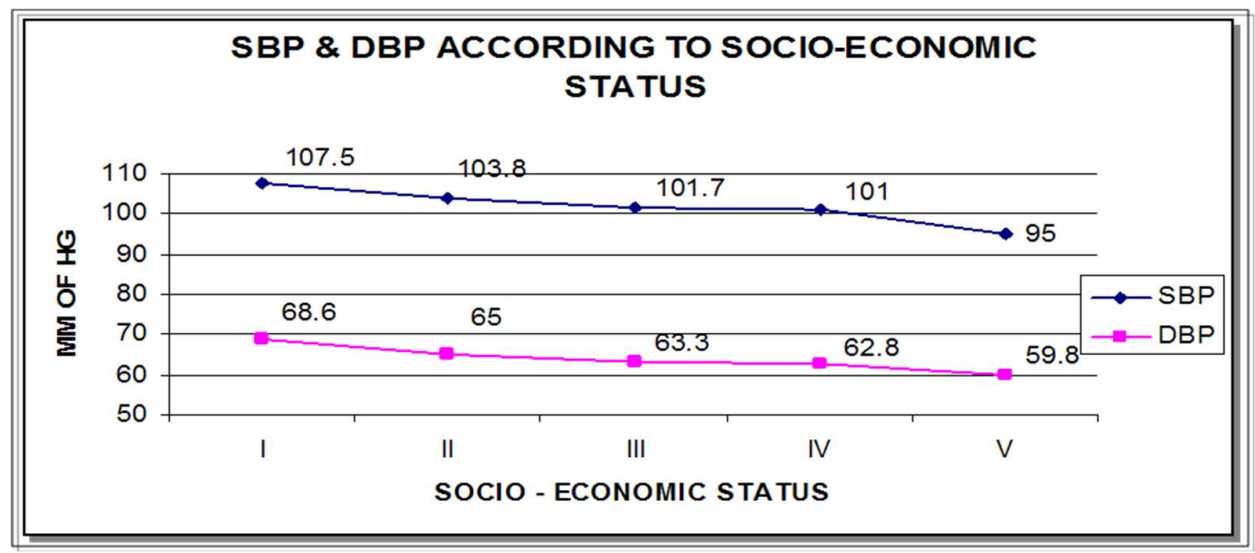

*SES Grading I-V: Modified Prasad socioeconomic status classification

Figure-5: Distribution of Blood Pressure According to Socio Economic Status. 
According to this study, there is high mean systolic and diastolic blood pressure in the children of high socio-economic status group. Mean SBP \& DBP in High Socio Economic Status (SES Grade I) are $107.5 \mathrm{~mm}$ of $\mathrm{Hg} \& 68.6 \mathrm{~mm}$ of $\mathrm{Hg}$ as compared to mean SBP of $95 \mathrm{~mm}$ of $\mathrm{Hg} \&$ mean DBP of $59.8 \mathrm{~mm}$ of $\mathrm{Hg}$ in Low Socio Economic Status SES- V, which is statistically highly significant $\mathrm{P}<0.001$.

\section{Discussion}

Blood pressure measurements in childhood are an important clinical examination which should be recorded at least once a year. However, it is not routinely employed in our country in various health checks up programs and studies pertaining to blood pressure of Indian school children are very few. There is little information available from southern part of the country especially in Telangana.

In our study, cut of value for hypertension was taken as greater than \& equal to 95 percentile as per the recommendations of fourth task force report on high blood pressure in children [8]. We found the prevalence of BP among children between $5-14$ years to be $7.2 \%$ (6.6\% in Boys \& $7.9 \%$ in girls) as compared to study done by Mohan B et al., [9] in Ludhiana (6.7 \%) and a higher prevalence (11.9\%) in a study done by Chadha S L et al., [10] from Delhi in the same age group.

Various Indian studies show diversity in prevalence of hypertension $(0.4 \%$ to $11.9 \%)$ which may be due to various racial sub groups, geographic, dietary and cultural factors and different criteria adopted for defining hypertension.

Following table shows the prevalence of hypertension in various studies.

\begin{tabular}{|c|c|c|c|c|}
\hline Study & Year & Age Group & Prevalence & Criteria \\
\hline Loroia et al [7] & 1986 & $5-14$ yr & $\mathbf{2 . 9 3}$ & $95^{\text {th }}$ percentile \\
\hline Gupta et al [6] & 1990 & $5-15$ yr & $\mathbf{1 . 3 9}$ & $95^{\text {th }}$ percentile \\
\hline Tandon et al [5] & 1996 & School children & $\mathbf{0 . 4 1}$ & $95^{\text {th }}$ percentile \\
\hline Chadha et al [4] & 1999 & $5-14$ yr & $\mathbf{1 1 . 9}$ & $\geq 95^{\text {th }}$ percentile \\
\hline Mohan B et al [14] & 2004 & $5-14$ yr & $\mathbf{6 . 7}$ & $\geq 95^{\text {th }}$ percentile \\
\hline Present study & 2016 & $5-14$ yr & $\mathbf{7 . 2}$ & $\geq 95^{\text {th }}$ percentile \\
\hline
\end{tabular}

According to fourth task force report on high blood pressure in children, values between $90 \& 95$ percentile should not be designated as 'High normal' but to be considered as 'Pre- Hypertension' [5, 6]. Our result revealed 4.7\% prevalence of Pre - hypertension with twice i.e., 6.2\% in Boys than in girls (3\%). There are no studies done for Prevalence of Pre Hypertension so far.

1. Age and its relation to blood pressure: An age limit of children in this study was 5-14 years. The present study revealed that rise in BP was directly proportional to increase in age in both sexes $(\mathrm{P}<0.001)$ (Figure 1). The correlation co-efficient of Girls and Boys for systolic and diastolic BP was 0.49 and 0.54 respectively. Similar observations were noted by other workers $[11,12,13]$.

The Task Force Committee report found the spurt between 5-6 years in both sexes. In our study, Spurt in SBP is noted between 7-8 yrs in both sexes and another spurt in SBP \& DBP was found in girls between 12- 13 years.

2. Weight and its relation to blood pressure: We found that both mean systolic and diastolic blood pressure increased with weight in boys and girls (Figure 2). Pearsons correlation coefficient was determined values $0.5 \& 0.47$ were noted for SBP \& DBP respectively which was highly significant. It is consistent with findings in other studies $[14,15]$

3. Height and its relation to blood pressure: Agarwal V.K et al., [15] showed that both systolic and diastolic BP was found to have direct correlation with weight, but not with height. But, we have observed that as the height increases, mean SBP \& DBP also increases proportionately, with a sharp rise in both systolic \& diastolic blood pressure above 110 $\mathrm{cm}$ of height in Boys \& Girls (Figure 3). Pearsons correlation coefficient was determined for height, values $0.53 \& 0.5$ noted for SBP \& DBP respectively which had highly significant positive correlation. 
Editorial

4. BMI and its relation to blood pressure: In boys and girls it was observed that the means of SBP and DBP in obesity group were significantly higher than overweight group while those in the overweight group has significantly higher values when compared to normal weight group (Table 2) $(\mathrm{P}<0.0001)$.

Similar observations were noted in studies done by Sachiel et al [11], Ribeiro et al [16], He Q et al (17) \& Wang et al [18]. Pearsons correlation coefficient shows values of $0.34 \& 0.28$ for SBP \& DBP respectively which has significant positive correlation, which can be compared well with the study done by Wang et al [18] ( $0.32 \& 0.24$ respectively).

5. Family History and its relations to blood pressure: In our study, $21.7 \%$ of children had positive Family History of hypertension. There is statistically significant higher level of systolic \& diastolic pressures in both sexes in children with Family history of adult Hypertension $(\mathrm{P}<0.001)$ (Figure 4) which had also been observed by Chadha et al [10], Mungar et al [19], and Londe et al [20].

Our study shows the prevalence of Hypertension in children with Positive family history of adult hypertension was $16.8 \%$ compared to $6 \%$ in those with normotensive parents. Similar observations were noted by Chadha et al [10].

6. Distribution of blood pressure according to socioeconomic status: Agarval R [21] found that there is no influence of socio-economic status on Blood pressure. As hypertension is becoming a serious public health concern in Ethiopia, it has to be given due concern in the health agenda of the country as one of top priority. Income does not play a direct role in increasing the odds of hypertension. Bethesda, Md ET AL., It rather influences the practice of risky behavioral factors that are responsible for hypertension. Therefore, promoting healthy lifestyles and interventions in lifestyle modifications related to the behavioral risk factors is recommended in reducing and controlling the prevalence of hypertension. It is clearly evident in our study that higher the grades of Socio economic status, higher are the mean SBP \& DBP $(\mathrm{P}<0.001)$ (Figure 5), which can be attributed to increase weight in this group of children. The values of mean SBP were $107.5 \mathrm{~mm}$ of $\mathrm{Hg} \& 95 \mathrm{~mm}$ of $\mathrm{Hg}$ in Grade I (High) \& Grade V (low) SES respectively and this was statistically highly significant.

\section{Conclusion}

Regular blood pressure measurement of children is mandatory for early detection of pre-hypertension \& hypertension. High Body mass index \& positive family history of hypertension forms an important indicator of childhood hypertension and appropriate therapeutic life style changes should be initiated to prevent hypertension \& its complications.

\section{Key Messages}

New outcome of the study: The Prevalence of Hypertension is significantly high in school children. Hence, it is mandatory to have regular Blood pressure measurements, at least once a year for early detection of Pre hypertension \& Hypertension.

High Body mass index \& Positive Family history of Hypertension form important risk factors of childhood hypertension.

Acknowledgements: To Nice Foundation School child health care plan programme team for smooth conduction of health camps and to Dr. Balakrishna, statistician NIN, Hyderabad for his statistical help.

Funding: Nil, Conflict of interest: None initiated, Perission from IRB: Yes

\section{References}

1. Hansen ML, Gunn PW, Kaelber DC. Underdiagnosis of hypertension in children and adolescents. JAMA. 2007 Aug 22;298(8):874-9.

2. Sheps SG, Roccella EJ. Reflections on the sixth report of the Joint National Committee on. Prevention, Detection, Evaluation, and Treatment of High Blood Pressure. Curr Hypertens Rep. 1999;1:342-5. PR.

3. Guyton, John E. Hall.-11th ed. p. ; cm. Includes bibliographical references and index. ISBN 0-72160240-1.

4. Sachdev Y. Normal blood pressure and hypertension in Indian children. Indian Pediatr. 1984 Jan;21(1):41-8.

5. Rames LK, Clarke WR, Connor WE, Reiter MA, Lauer RM. Normal blood pressure and the evaluation of sustained blood pressure elevation in childhood: the Muscatine study. Pediatrics. 1978 Feb; 61(2): $245-51$.

6. Jaddou HY, Bateiha AM, Khawaldeh AM, Goussous YM, Ajlouni KM. Blood pressure profile in schoolchildren and adolescents in Jordan. Ann Saudi Med. 2001 Jan-Mar;21(1-2):123-6. 
Editorial

7. Subhi MD. Blood pressure profiles and hypertension in Iraqi primary school children.Saudi Med J. 2006 Apr; 27 (4):482-6.

8. Mohan B, Kumar N, Aslam N, Rangbulla A, Kumbkarni S, Sood NK, Wander GS. Prevalence of sustained hypertension and obesity in urban and rural school going children in Ludhiana. Indian Heart J. 2004 Jul-Aug;56(4):310-4.

9. Chadha SL, Tandon R, Shekhawat S, Gopinath N. An epidemiological study of blood pressure in school children (5-14 years) in Delhi. Indian Heart J. 1999 Mar-Apr;51(2):178-82.

10. Schiel R, Beltschikow W, Kramer G, Stein G. Overweight, obesity and elevated blood pressure in children and adolescents. Eur J Med Res. 2006 Mar 27; 11 (3):97-101. PubMed PMID: 16751109.

11. Anand NK, Tandon L. Prevalence of hypertension in school going children. Indian Pediatr. 1996 May;33 (5): $377-81$.

12. Gupta AK, Ahmad AJ. Childhood obesity and hypertension. Indian Pediatr. 1990;27(4):3337. 30.

13. Laroia D, Sharma M, Diwedi V, Belapurkar KM, Mathur PS. Profile of blood pressure in normal school children. Indian Pediatr. 1989 Jun; 26 (6):531-6.

14. Agarwal V.K, Rajiv Sharan, Srivastava A.K, Prem Kumar Pandey C.M. Blood Pressure Profile in Children of age 3-14 years. Indian Pediatrics 1983;20; 921-925.
15. Ribeiro J, Guerra S, Pinto A, Oliveira J, Duarte J, Mota J. Overweight and obesity in children and adolescents: relationship with blood pressure, and physical activity. Ann Hum Biol. Mar-Apr 2003;30 (2): 203-213.

16. He Q, Ding ZY, Fong DY, Karlberg J. Blood pressure is associated with body mass index in both normal and obese children. Hypertension. 2000 Aug;36 (2): 165-70.

17. Wang WJ, Wang KA, Chen CM, Cao RX, Bai YM, Ma LM, Ren ZY, Niu ZH, Gao Q. [The study on relationship of body mass index and blood pressure in children and adolescents of Beijing]. Zhonghua Liu Xing Bing Xue Za Zhi. 2004 Feb;25(2):109-12.

18. Munger R.G., Rineas RJ, Gomez-Mamo. Persistent evaluation of blood pressure among children with family history of hypertension. J. Hypertens, 1988;6: 647-653.

19. Londe S, Bourgoignie JJ, Robson AM, Goldring D. Hypertension in apparently normal children. J Pediatr. 1971 Apr;78(4):569-77.

20. Chahar CK, Shekhawat V, Miglani N, Gupta BD. A study of blood pressure in school children at Bikaner. Indian J Pediatr. 1982 Nov-Dec;49(401):791-4.

21. Agarwal R, Mandowara S.L. Bhandari B, Gar O.P. Prevalence of hypertension in apparently health school children. Indian Pediatrics.1982;19: 779-784.

\section{How to cite this article?}

Koolla Pavan Kumar, S. Srikrishna, P. S. Murthy, Reddy P. Biophysical profile of blood pressure in urban school children. Int J Pediatr Res. 2018;5(2):48-54. doi:10.17511/ijpr.2018.i02.02. 